Int. J. Electrochem. Sci., 11 (2016) $6597-6608$

\title{
A Novel Iron(III) Potentiometric Sensor Based on (E)-N'-((2- hydroxynaphthalen-3-yl)methylene)benzohydrazide
}

\author{
Abdollah Yari ${ }^{1, *}$, Marzieh Bagheri ${ }^{1}$ and Mahdieh Ghazizadeh ${ }^{2}$ \\ ${ }^{1}$ Department of Chemistry, Faculty of Science, Lorestan University, Khorramabad-Iran. \\ ${ }^{2}$ International Center for Science, High Technology \& Environmental Sciences, Kerman-Iran \\ *E-mail: a.yari@ymail.com
}

doi: $10.20964 / 2016.08 .02$

Received: 9 April 2016 / Accepted: 21 May 2016 / Published: 7 July 2016

Here, we report the design and application of a new PVC membrane electrode, based on (E)-N'-((2hydroxynaphthalen-3-yl)methylene)benzohydrazide as a reliable complexing agent, for determination of iron(III) ion. The electrode illustrates an excellent Nernstian slope of $19.9 \pm 0.3 \mathrm{mV} /$ decade over a wide linear range of concentration from $5.0 \times 10^{-9}$ to $1.0 \times 10^{-2} \mathrm{M}$ with a detection limit of $1.0 \times 10^{-9} \mathrm{M}$ of $\mathrm{Fe}^{3+}$ in solution. The tolerable $\mathrm{pH}$ range of 2.4 to 4.0 , response time of $10 \mathrm{~s}$ and measurement stability for 3 months is valuable characteristics of the sensor. The analytical application of the sensor was successfully tested by potentiometric titration of a Fe(III) solution with EDTA in some water samples. The accuracy of given measuring data was tested by determination of $\mathrm{Fe}^{3+}$ in some water solutions from different resources with both the sensor and an atomic absorption spectrometer, as a standard method. The results were well comparable. We inform a reliable device that provides a simple method to determine $\mathrm{Fe}^{3+}$ ion in a fast manner with high accuracy.

Keywords: Benzohydrazide; Iron(III); Potentiometric sensor; PVC membrane

\section{$\underline{\text { FULLTEXT }}$}

(C) 2016 The Authors. Published by ESG (www.electrochemsci.org). This article is an open access article distributed under the terms and conditions of the Creative Commons Attribution license (http://creativecommons.org/licenses/by/4.0/). 